\title{
The influence of Facebook advertising on cognitive attitudes amid Generation Y
}

\author{
Rodney Graeme Duffett
}

Published online: 30 January 2015

(C) The Author(s) 2015. This article is published with open access at Springerlink.com

\begin{abstract}
Social media has irrevocably transformed the manner in which society communicates and has altered perceptions and attitudes. The proliferation of Facebook usage has connected consumers to each other, to marketers and to brands in a manner that is as inventive, and has altered the world as we know it. However, research on Facebook is still in its infancy in an emerging country such as South Africa. Generation Y is a significant consumer group and, consequently, their attitudes towards social media advertising are of significant importance to marketers. This has triggered the question whether the largest social medium's marketing communications effectively reaches young adults in South Africa, and what influence it has on their cognitive attitudes, which leads to their buying behavior. The results suggest that Facebook advertising has a favorable effect on the awareness and knowledge hierarchy-of-effects model levels amongst Generation Y in South Africa. The research is beneficial to marketers who intend to make use of this powerful conduit to target this vacillating cohort.
\end{abstract}

Keywords Facebook advertising - Generation Y · Awareness · Knowledge · Cognitive attitudes $\cdot$ South Africa

\section{Introduction}

Marketing communication plays an integral part in the survival of companies in this global recessionary aeon. The past decade has seen a major shift of marketing communication budgets from traditional to more digital interactive media such as the Internet and social media in order to reach a huge number of consumers, especially the fickle

R. G. Duffett $(\varangle)$

Marketing Department, Faculty of Business, Cape Peninsula University of Technology, P O Box 652,

Cape Town 8000, South Africa

e-mail: duffetr@cput.ac.za 
cohort known as Generation Y (aged eighteen to early thirties). A majority of this cohort regularly interacts on the world's largest social network site (SNS), Facebook, which had 1.35 billion monthly active users in September 2014 [24] and forecasted global Facebook advertising revenue of $\$ 9$ billion in 2015. There are 11.8 million Facebook users in South Africa [69] and online advertising revenue is expected to increase by $25 \%$ per annum, which is twice the global average. Furthermore, South African consumers are anticipated to spend in the region R60 billion online by 2017 [67]. Therefore, it is important that companies should carefully consider what the younger generation's perceptions of their brands are on SNS platforms and what type of communication would be most stimulating and engaging for the youth market [15]. However, many South African marketers do not have a full understanding of how effective it is or whether SNS are more or less effective compared to other marketing communication platforms [34]. Moreover, click-through rate is the customary online metric measurement tool, but many marketers want to understand what occurs after the click in order to establish how to attribute an activity when it occurs, as well as how to direct advertisements to consumers.

Consumers' attitudes towards Facebook advertising is important, especially in terms of the type of activity that marketers want to encourage. Numerous studies have investigated online advertising effectiveness $[10,27,65,70]$; however, these studies' focus was on the context of traditional online sites. Traditional online site advertising primarily use banner advertisements and sponsored links, whereas social network advertising (SNA) is often not discernible from user content. These inquiries from different online environments may prove inadequate; hence, SNA warrants research that is inherent to this new digital medium. Therefore, the rapid growth of SNS usage and increasing advertising expenditure necessitate that separate investigations on consumers' perceptions should be explored in the context of SNS, as they ultimately determine attitudes, which influence their purchasing behavior [61].

Bolton et al. [8] postulate that Generation Y attitudes towards SNS, as well as their usage characteristics may be divergent in comparison to emerging countries owing to diverse cultures and less developed technological infrastructure. SA has been a leader of information and communication technology in Africa, but in recent years has seen a decline as a result of low fixed-line penetration (because of high prices that are charged by the state-owned telecommunication operator); poor broadband penetration growth and slow broadband speeds; low Internet access in spite of the rapid growth of access via mobile devices; and poor computer access in households [36]. Notwithstanding, Generation Y's attitudes towards SNS and usage patterns are of keen interest to marketers as it may suggest future consumer behavior patterns, including their predispositions towards their brands. Accordingly, this research intends to determine if Facebook advertising is effective to realize the first two stages of the hierarchy-of-effects models, awareness and knowledge (viz. the cognitive attitude) among the Generation Y cohort in SA. Bolton et al. [8] propose that prior enquiries about SNS among Generation Y resulted in more questions than answers. Research on SNA is still in its exploratory stage, especially in developing countries such as SA. A majority of studies that have investigated various aspects of SNA have been conducted in Europe and the United States (US) [3,4,30,31,38,39,50,66], while the fastest growing SNS audiences are in emerging regions such as Africa, the Middle 
East and Asia-Pacific, where SNS use may differ significantly [22]. Consequently, this study aims to provide insights into Facebook advertising's impact from a SA perspective, where a quarter of the population can be categorized into Generation Y cohort [58].

Additionally, Bolton et al. [8] disclose that most of the investigations utilized student research populations whose consumer behavior may alter considerably as they pass though different phases of their life cycle. This study surveyed a more representative range of the Generation Y cohort, as mandated by Jordaan et al. [32], which consisted of young working professionals and unemployed individuals (the unemployment rate is $50 \%$ amongst this cohort [58] from both rural and urban areas in the Western Cape. Furthermore, respondents from both the suburbs (more advantaged areas) and townships (also incorporating informal settlements) were surveyed, instead of only using a student research population in order to obtain a more representative sample of Generation Y. Bolton et al. [8] also queried as to whether there were perceptible divergent characteristics among Generation Y subcategories. Hence, the impact of various usage and demographic factors of the Generation Y cohort were also examined and cross analyzed in this study.

This paper is structured as follows: the next section discusses and provides background information about the research questions; thereafter, recent literature on Facebook marketing communications, Generation Y, the hierarchy-of-effects model and attitudes are explored; followed by the methodology; results; discussion; theoretical and practical implications; and limitations and future research sections.

\section{Research questions}

Accordingly, this empirical study endeavors to expand upon the following research questions (RQ):

RQ1: What effect does Facebook advertising have on the cognitive attitudinal component of Generation $\mathrm{Y}$ in an emerging country such as SA?

The consumer passes through consecutive phases in response to advertising: awareness, knowledge, liking, preference, conviction/intention-to-purchase and purchase. The phases of the hierarchy-of-effects model are equivalent to the communications of effect pyramid model, so by initially attaining lower hierarchy response marketing communication objectives such as awareness and knowledge, it becomes increasingly more challenging to attain higher level stages. Therefore, the number of potential consumers decreases, as they move through the final stages of the pyramid until the eventual purchase [5]. However, these theoretical models were derived from traditional advertising, whereas this inquiry will concentrate on the latest digital interactive online media to establish consumers' cognitive attitudes as they progress through the lower levels of the aforesaid theories. Therefore, this study is significant to a majority of South African companies that have invested substantial amounts of their marketing budgets in Facebook advertising, and the need to determine advertising on this SNS has a favorable influence on the aforementioned cognitive attitudes. This empirical research is also important for researchers and academics, since there is a lack of research on SNS attitudinal advertising among Generation Y in developing countries, 
according to Bolton et al. [8] and Okazaki and Taylor [43]. Hence, it will make a significant contribution to the conceptual framework of attitudinal research on SNA. Furthermore, the growth of Facebook has begun to slow in many first world countries, whereas Facebook use is still rapidly increasing in emerging nations such as SA, with a growth rate of nearly $40 \%$ over the past year [68].

RQ2: How do various Facebook usage characteristics influence Generation Y's awareness and knowledge perceptions of advertising on Facebook in SA?

Almost nine out of ten Facebook users access this SNS through mobile phones in SA [68]; therefore, it would be of importance to establish if there was a significant difference between Generation Y's attitudes regarding how they accessed the Facebook. Other usage factors that were investigated to determine whether they have an influence on Generation Y's awareness and knowledge perceptions of advertising on Facebook include: length of usage, $\log$ on duration, $\log$ on frequency and profile update incidence. Several studies have ascertained various usage characteristics of SNS users in SA, but few have investigated Facebook individually or ascertained if these variables had an influence on advertising [14,16,32,52]. Additionally, there is a dearth of global inquiry that has investigated the influence of usage factors on Facebook advertising. This research is relevant for both organizations and academics alike, since it will provide a greater understanding of Generation Y's SNS usage factor tendencies, and whether these have an impact on their cognitive attitudes, which will provide increased insight into future potential consumer behavior of Generation Y in SA.

RQ3: Do various demographic factors have an impact on Generation Y's cognitive attitudes towards Facebook advertising in SA?

As commissioned by Bolton et al. [8], the aim of this research is to determine whether there are significant differences within and amongst Generation Y subgroups regarding cognitive attitudes towards advertising on Facebook. Therefore, this study aims to establish if demographic variables such as: gender, age and ethnic orientation) have an impact on Generation Y's awareness and knowledge perceptions of Facebook advertising. A number of inquiries described the demographic factors of South African SNS users, but did not take advertising into cognizance or consider Facebook as a single entity $[6,14,16,32,52]$. Furthermore, little international research has examined the influence of demographic factors, particularly age (within a specific cohort) and ethnic orientation regarding attitudinal research. Moreover, the ethnic orientation examination will be of keen interest to originations and academics owing to the well documented atrocities of the past that transpired in SA, which caused a considerable economic divide.

\section{Literature review}

Marketers have realized that Facebook has huge potential as a marketing communications platform, which enables them to reach and personally integrate with millions of their customers by the creation of their own Facebook pages and/or utilize the many advertising opportunities offered by Facebook [25,40]. Econsultancy and Adobe [19] reported that $86 \%$ of organizations that were surveyed across the globe maintained 
a presence on Facebook. Furthermore, more than $60 \%$ of the respondents stated that they used social media as a brand awareness conduit. JustPlay [33] established that $34 \%$ of Facebook users would click on an advertisement if there was an opportunity to win a prize or receive giveaways, in comparison to $18 \%$ who would view an advertisement that they found interesting and $12 \%$ for an advertisement that offered a discount. Facebook marketplace advertising click-through rates were only between 0.021 and $0.045 \%$ in first world countries, however, a global marketer that used mobile Facebook advertising in SA received click-through rates of more than $5 \%$ $[7,62]$. Many Facebook marketers are beginning to focus less on increasing clicks and placing greater emphasis on what transpires post click. The motive for this phenomenon is to establish how to attribute an activity when it transpires, as well as how to use advertisements to target people, depending on what type of activity they want to occur. Consequently, this research heeds this call and focuses on cognitive attitudes, since these have a significant influence on consumer behavior. The South African Social Media Landscape 2014 study reveals that $93 \%$ of brands have some type of Facebook presence, however, on the contrary, only $52 \%$ believe that their efforts on Facebook are effective [68].

Generation Y continuously use technology such as Bluetooth, GPS, 3G and 4G, online gaming, iTunes to download music and other numerous applications. Social media has empowered Generation $\mathrm{Y}$ to be more active in the marketing of brands via electronic WOM, writing reviews, product feedback and "liking" their favorite brands [56]. Several inquiries have examined Generation $Y$ in terms of various elements and confirmed high usage of social media in SA: Jordaan et al. [32] compared South African Generation Y consumers' perceptions towards traditional media in comparison to online conduits such as SNS in terms of credibility; Shambare et al. [52] explored the SNS usage characteristics of students; Ramnarain and Govender [49] examined social media usage patterns and among the youth, as well as the use of this interactive platform to influence online purchases; Dlodlo and Dhurup [16] considered the enjoyment, ease of use and usefulness of social media in terms of the technology acceptance model; and Chikandiwa et al. [11] assessed South African banks' adoption and implementation of social media marketing. Generation $\mathrm{Y}$ in SA is not easy to categorize and represents a complex challenge to marketers. They will achieve a lot in different ways compared to prior generations, but similar to other Generation Y's from different countries, cultures and races, as global influences increase, as theorized [57]. Generation $Y$ is deemed to be a homogenous global cohort [41], but there has been deliberation as to whether this philosophy is accurate, especially since developed countries have superior infrastructure, technology and wealth compared to emerging countries $[36,45]$. This cohort comprises of almost $25 \%$ of the SA population [58], but these young consumers account for less than $20 \%$ of marketing communication budgets. Generation Y spends in excess of R104 billion per annum [37]. A majority of Facebook users are aged 1834 years old, which is especially beneficial to organizations that target young adults [68]. This generation is generally more comfortable with spending online and usually has some disposable income available [13]. Members of the Generation Y cohort who are 18-20 years old are referred to as "born frees" since they were born after the first democratic elections in 1994. The 21-24 age group category mainly constitute students and young adults who are entering the work place, whereas 25-30 year olds 
are predominantly working (or seeking work) and, therefore, generally have the most discretional income. The research seeks to establish if there was a difference between these age groups, and whether it was unique in terms of the SA context. The Black Generation Y cohort encompasses a significant portion of the South African market, nearly 11 million individuals, which represent $83 \%$ of Generation Y and over $20 \%$ of the total population [58], and especially those who are studying at tertiary institutions represent a particularly lucrative target market owing to the fact that higher education is correlated with increased earning potential [6]. However, marketing communication campaigns must be customized to fit the African target market's unique needs; it is not enough for brands to simply maintain a presence on the SNS [15], hence further research is warranted to fully understand this cohort in SA.

The hierarchy-of-effects model indicates that advertising effects occur over a period of time and some researchers postulate that the immediate effect of advertising on sales is generally low $[1,63]$. Therefore, advertising may not lead to the immedi-ate purchase of a product, but the sequence of effects should occur for each phase before the consumer moves to the next stage in the hierarchy. Wang and Sun [65] found that appropriate online advertising management will improve the cognitive component of consumer behavior. The cognitive component can be described as consumers becoming aware of the existence of the brand and then searching for brand-related content on websites to gain more knowledge, which is the focus of this investigation. Table 1 below provides an overview of the most current attitudinal research on SNA in terms of the research objectives that specifically relate to awareness and knowledge hierarchical levels; research methodology; the main results pertaining to cognitive attitudes; and the chief limitations/disadvantages.

Hence, in summary, there have been a number of inquiries, which examine attitudes towards SNA that were largely conducted in the US and/or Europe; students were predominately used as the research population; several small sample sizes were employed; none investigated the influence of usage characteristics; and few examined the impact of SNA on gender, whereas none explored the effect of demographic factors such as age (within a cohort) or ethnic orientation on Facebook advertising.

\section{Methodology}

\subsection{Research design}

The research design is descriptive in nature and utilizes the survey method for this study. Descriptive research is used to describe the problem that is researched, as well as variables such as the attitudes of individuals towards an object (that is, Generation Y's cognitive attitudes towards Facebook advertising) and their demographics by taking a cross sectional segment of the target population to determine the frequency with which something occurs and/or the relationship between two variables [12]. This type of research is typically conducted when knowledge of the study object is vague or unclear-little is known about cognitive attitudes towards Facebook advertising in SA. The survey method would be preferable for this investigation owing to the nature of the research problem and the viability of market information. Therefore, 


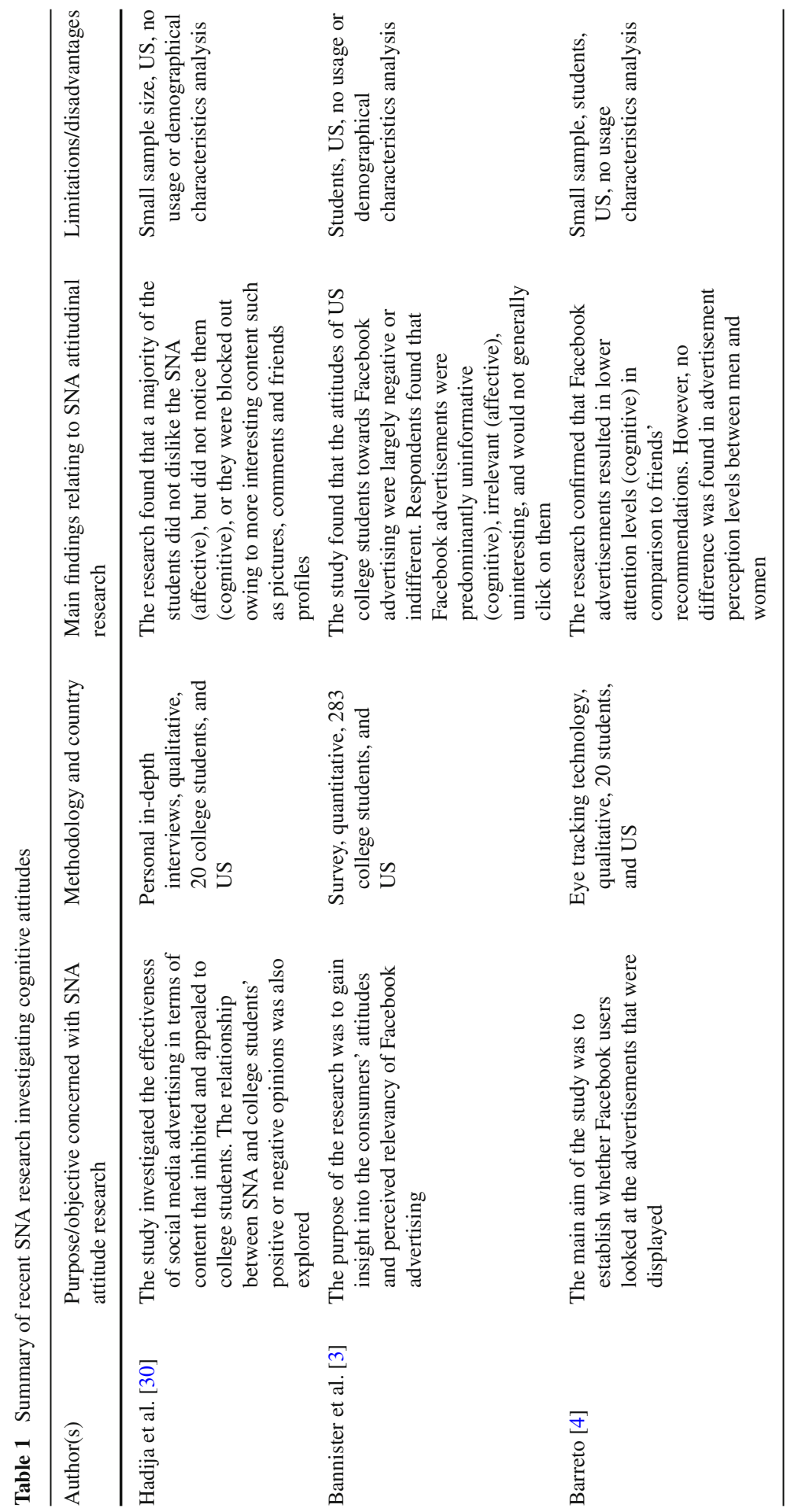




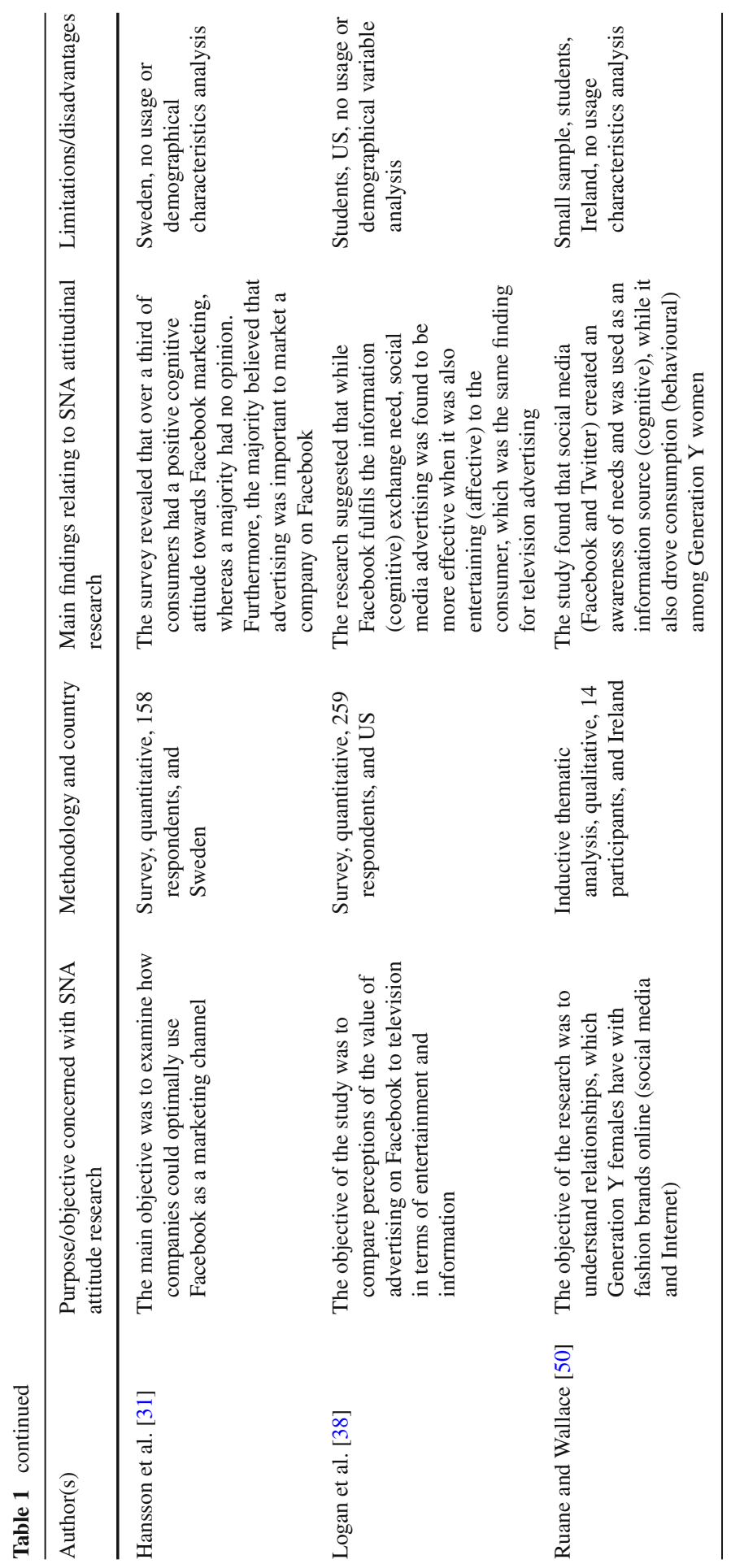




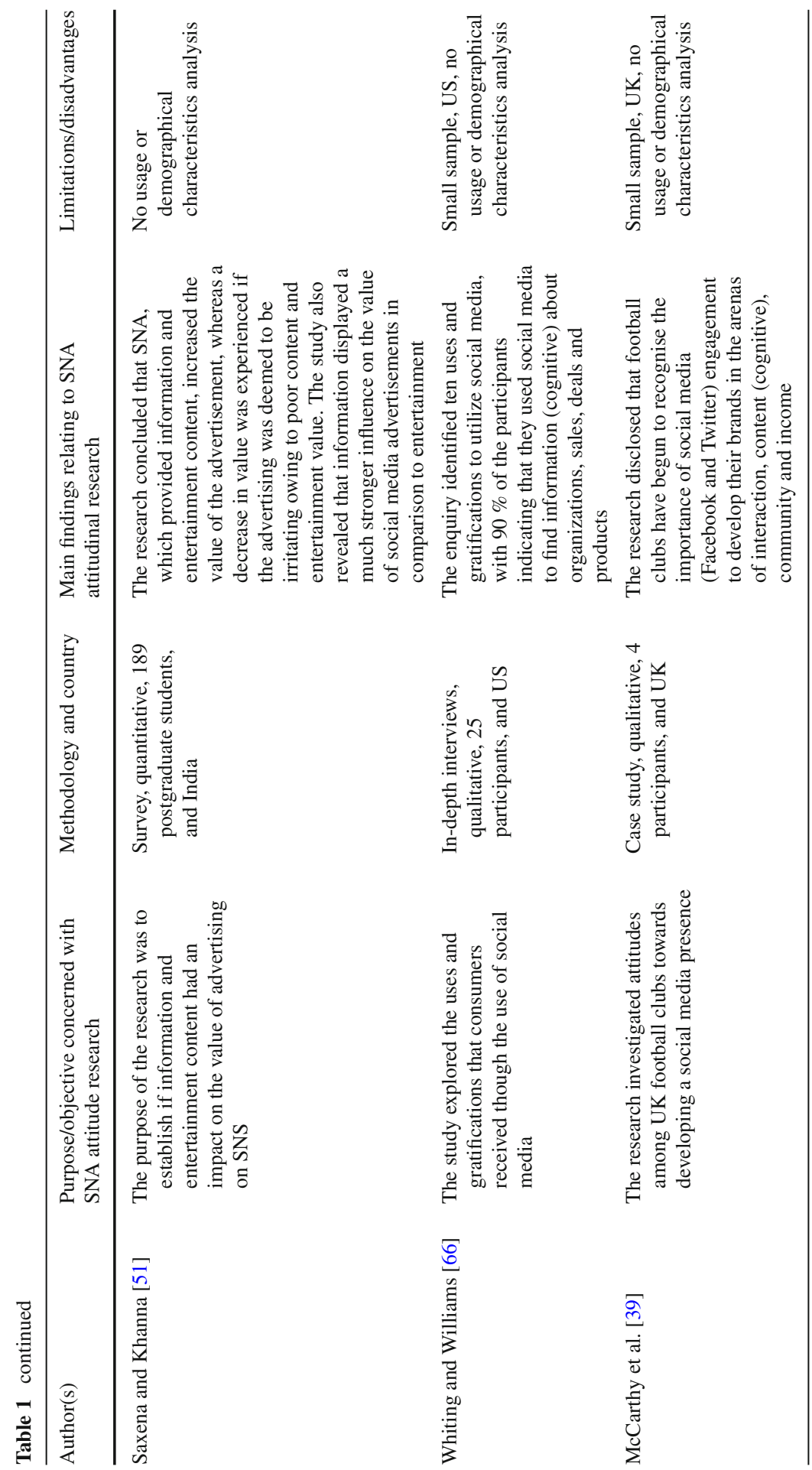


self-administered questionnaires were disseminated on a face-to-face basis to gather data for this research study.

\subsection{Sampling}

A number of studies have identified Generation $\mathrm{Y}$ as the main users of online digital and online technological gadgets and innovations such as SNS and mobile applications and, consequently, a target market for online marketers [16,30,38,49,61]. Furthermore, several studies have revealed that students are the primary users of SNS $[32,51,52,57]$, and are hence exposed to advertising on SNS such as Facebook. However, Jordaan et al. [32] believed that it was important to draw a more representative sample of Generation Y, other than solely selecting students to participate in the study. Therefore, the research population comprised of young working adults, young adults who had completed school, but were still seeking employment (nearly one in three people in SA are unemployed, with up to half of Generation Y for certain age categories within this cohort) [58], as well as students, to ensure adequate representation of Generation $\mathrm{Y}$ that had used Facebook and had perceived advertising on this SNS. The sample frame included Generation Y members who reside in the Western Cape that account for $11.25 \%$ of SA's population [58]. The research utilized a multiphase sampling technique, which also is referred to as double sampling or sequential sampling [12]. Firstly, the Cape Peninsula was divided into different geographic locations (clusters), which included both rural and urban, as well as suburban (typically more affluent areas) and townships (including informal settlements) areas, by using a regional map. Secondly, businesses, tertiary education institutions and community organizations (churches, sports clubs, and youth groups) were identified by means of a telephone directory and were randomly selected. Thereafter, these organizations were contacted telephonically to obtain approval to conduct the survey on their premises and to establish that there was a sufficient number of the Generation Y cohort to interview (mainly in terms of businesses, since the other aforementioned organizations were well represented by the Generation Y owing to their inherent nature). Thirdly, systematic sampling was utilized to survey respondents in the abovementioned organizations, and every third respondent was invited to voluntarily participate in the study.

\subsection{Questionnaire design and data collection}

A structured self-administered questionnaire was utilized to acquire the considerable amount of data that was required for the study in an efficient way. Respondents for this research study were first required to answer two screening questions before they were permitted to participate in the survey (refer to Table 2 below). However, respondents were not required to list the featured services, products or brands in the advertisements, nor was any differentiation made between types of Facebook advertising.

The next part of the questionnaire comprised of five multiple-choice questions on SNS usage characteristics (independent variables) listed in Table 2 below. An eighteen item scale to measure awareness and knowledge (dependent variables) was mainly adapted from Ducoffe [17] and Duncan et al. [18], which forms the second part of the 
Table 2 Questionnaire questions overview

\begin{tabular}{ll}
\hline Question categories & Questions \\
\hline Screening & Do you use Facebook? \\
& Have you noticed any advertising on \\
& Facebook? \\
Usage factors & How do you access Facebook? \\
& How long have you used Facebook? \\
& How often do you log on to Facebook? \\
& How many hours do you spend on \\
& Facebook per log-in? \\
& How often do you update your Facebook \\
& profile? \\
& Refer to Table 4 to view the nine \\
Awareness construct & awareness construct items \\
Knowledge construct & Refer to Table 5 to view the nine \\
& knowledge construct items \\
Demographic factors & Gender \\
& Age \\
& Ethnic orientation
\end{tabular}

questionnaire, in other words, the first and second levels of the hierarchy-of-effects model (collectively referred to as the cognitive attitude component). Responses were measured on a five-point Likert scale, where items ranged from strongly disagree to strongly agree. The final part of the research instrument included three multiple-choice questions, which relate to demographic factors (independent variables) listed in Table 2 above. A pre-test, which included one hundred respondents, was implemented in order to test the reliability of the research instrument, refine the scales and ensure that the multiple-choice questions catered for all possible responses. Thereafter, a pilot study of another one hundred respondents was conducted to ensure the efficient operation of other elements (such as sampling, analysis and methodology) of the research process. A total of 21 fieldworkers (Baccalaureus Technologiae: Marketing students at the Cape Peninsula University of Technology were required to complete a year course in marketing research and received extensive work experience as fieldworkers for the full duration of the course) were deployed to different areas from April to June 2013 in order to conduct the primary research, and were closely supervised by the researcher. Hence, a total of 3634 useable questionnaires were completed over three months (incomplete or spoilt questionnaires were discarded).

\subsection{Data analysis}

The collected data was coded, captured and analyzed by means of the statistical program known as SPSS (version 21). All completed questionnaires were thoroughly scrutinized to decide whether they should be included in the survey analysis in terms of completeness and correctness - the Likert scale questions were structured in such a 
way that negative and positive questions were constantly alternated in order to prevent respondents from merely selected a single column. These statements were reversed by using SPSS, before Cronbach's Alpha was used to determine the reliability of the responses for the Likert scale. Basic descriptive statistical measures (frequencies, means, standard deviations and non-parametric one-sample bi-nominal standardized test) were used to describe the findings [26] (Tables 3, 4, 5), whereas Pearson's correlation coefficient analysis was utilized to determine the strength of the relationship between variables [44] (Tables 4, 5). A generalized linear model (GLM) analysis of variance (ANOVA), using the Wald's Chi-square and the post ad hoc Bonferroni pairwise comparisons were used to determine if there was a significant difference between the aforementioned variables [26] (Tables 6, 7).

\section{Results}

A total of 3,634 members of the Generation Y cohort were surveyed in the Western Cape. A majority of respondents $(62.5 \%)$ accessed Facebook by means of both PC and mobile device, habitually logged on to Facebook daily $(61.9 \%)$, spent one $(48.3 \%)$ to two $(27.4 \%)$ hours per session and $75 \%$ updated their profile at least once a week. The sample was marginally dominated by females $(55.9 \%)$; a near majority of the respondents were "born-frees" $(45.6 \%)$, and the population groups reflected the ethnicity in the Western Cape with Black $(54.9 \%)$ and Colored $(25.5 \%)$ in a majority [58]. Table 3 below provides a complete overview of Facebook usage characteristics and demographics of the Generation Y respondents.

As mentioned in prior text, the respondents' cognitive attitude towards Facebook advertising was measured by nine-item scales for each of the hierarchy-of-effects model levels (refer to Tables 4, 5 below).

A reliability assessment of the awareness and knowledge scales was undertaken by utilizing Cronbach's $\alpha$. Cronbach's $\alpha$ is the most common objective measure of reliability, and measures the amount of internal consistency between variables that measure one construct. Values that are over 0.7 are deemed to be acceptable, but any score above 0.8 is desirable [44,59]. Three negatively phrased statements were included in each scale, which was important to reduce response bias, but were reversed, or else they would have negatively influenced the Cronbach's $\alpha$ outcome [26]. Cronbach's $\alpha$ was 0.857 for Facebook's advertising awareness scale (Table 4 below) and 0.837 for the knowledge scale (Table 5 below), reflecting good internal consistencies. The means for awareness and knowledge also showed that respondents tended to "agree" that Facebook advertising caused awareness and resulted in knowledge. A principle component analysis was conducted to provide a measure of validity regarding the two cognitive attitude constructs. The first principle components of the awareness and knowledge constructs represented 67.2 and $63.7 \%$ of the variance and the second principle components 19.4 and $21.9 \%$, thereby accounting for 86.2 and $85.6 \%$ of the variance in the data, which indicated that there was little divergence in the construct items. The awareness and knowledge construct items all have a relatively high contribution in terms of the first principle components, with coefficients ranging from $0.711-0.887$ and $0.652-0.874$ respectively. This shows that the measured variables 
Table 3 Facebook usage characteristics and demographics
Facebook usage characteristics

$\mathrm{n}$

$\%$

Access

Mobile device

834

22.9

PC

529

14.6

Mobile device \& PC

2,271

62.5

Length of usage

$\leq 1$ year

489

13.5

2 years

853

23.5

3 years

961

26.4

4 years

706

19.4

$\geq 5$ years

625

17.2

Log on frequency

Daily

2,250

61.9

2-4 a week

842

23.2

Once a week

374

10.3

2-4 a month

90

2.5

Once a month

Log on duration

$\leq 1 \mathrm{~h}$

1,757

48.3

$2 \mathrm{~h}$

994

27.4

$3 \mathrm{~h}$

422

11.6

$4 \mathrm{~h}$

207

5.7

$\geq 5 \mathrm{~h}$

254

7.0

Profile update incidence

Daily

1,090

30.0

2-4 a week

937

25.8

Once a week

698

19.2

2-4 a month

369

10.1

Once a month

540

14.9

Demographics

Gender

Male

1,603

44.1

Female

2,031

55.9

Age

18-20

1,658

45.6

21-24

1,369

25-30

607

16.7

Ethnic orientation

White

531

14.6

Black

1,997

54.9

Colored

926

25.5

Indian/Asian

180

5.0 


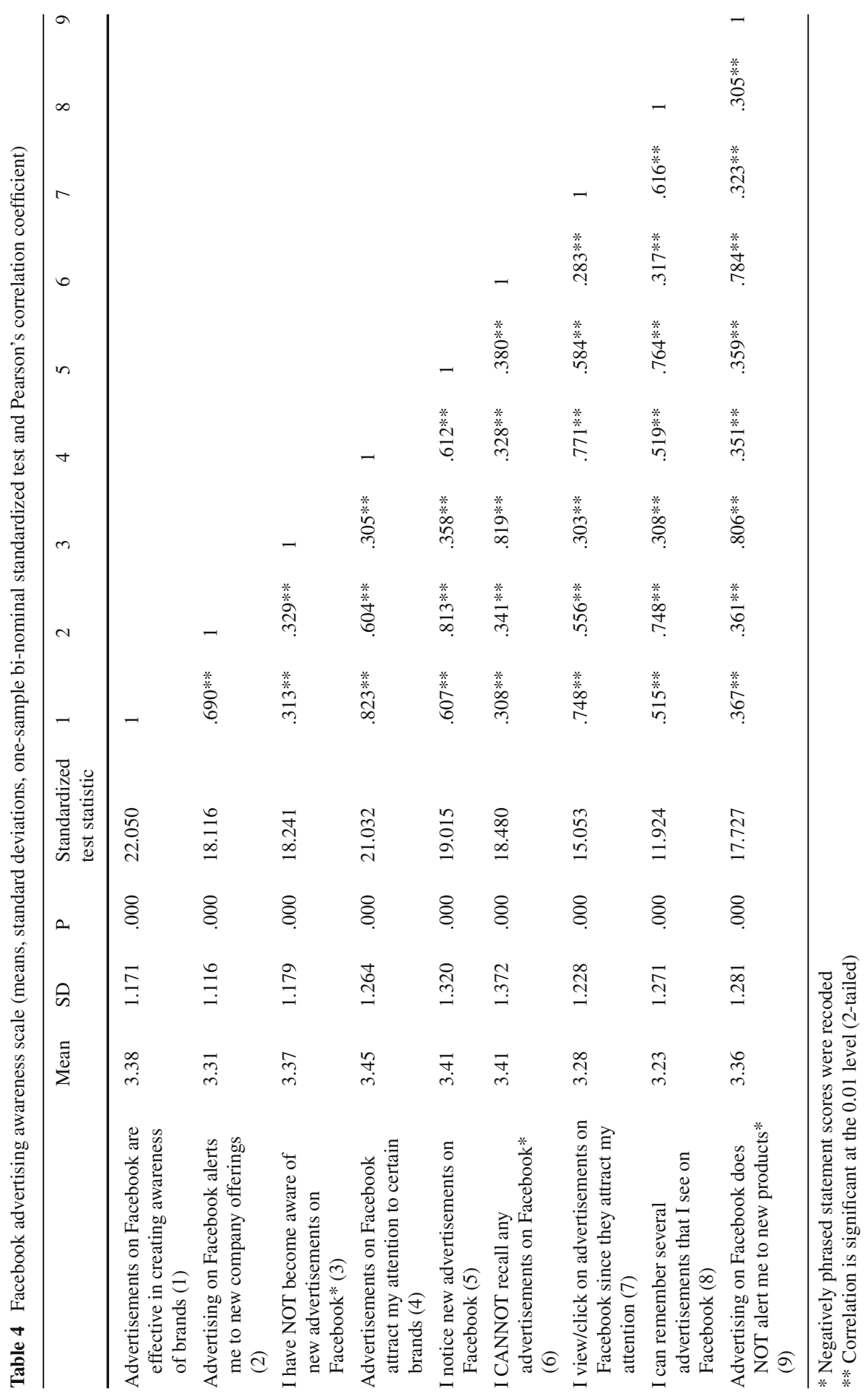




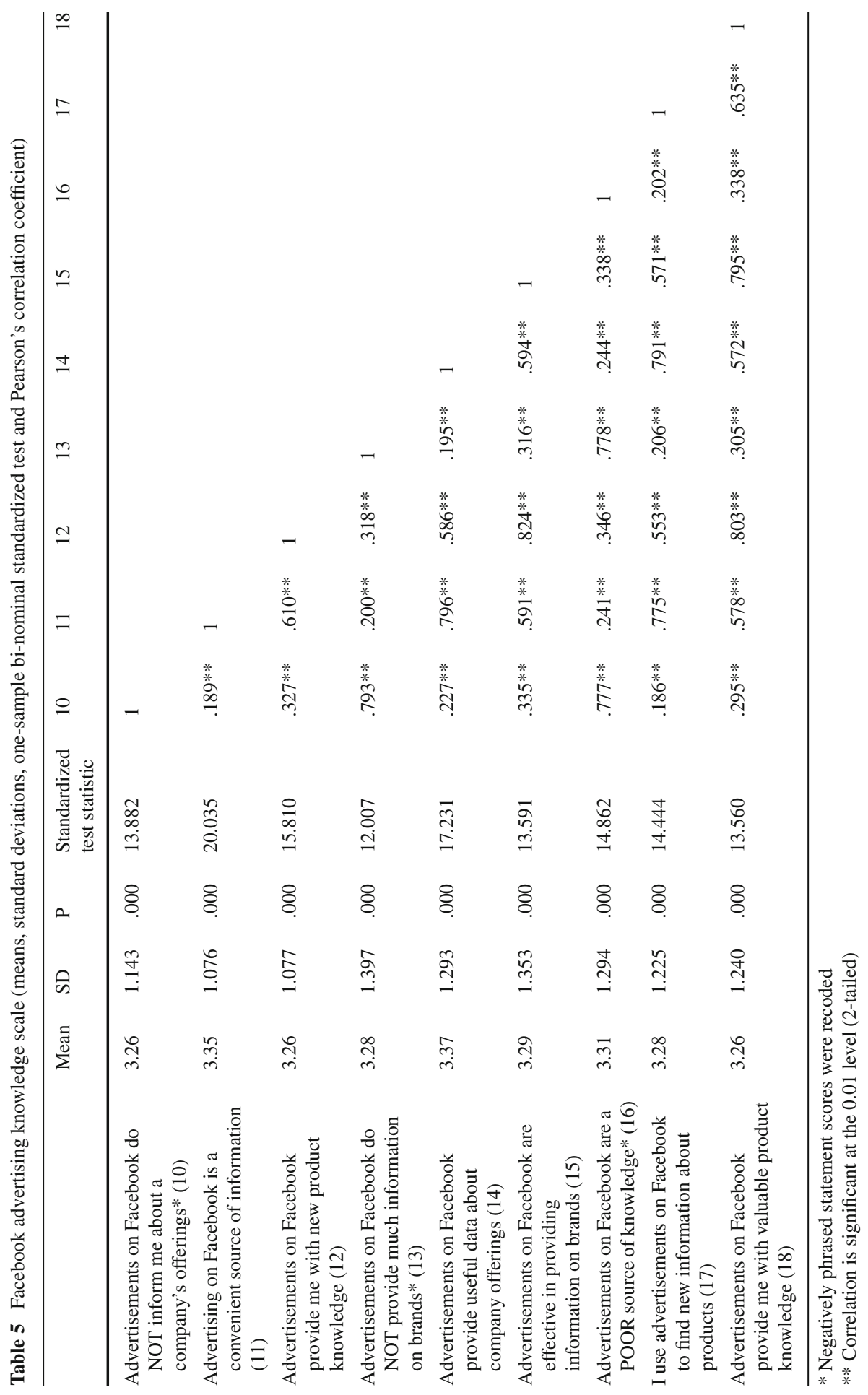


Table 6 Effect of usage characteristics and demographics on Facebook advertising awareness

* Wald Chi-square test showed a significant difference at $\mathrm{p}<0.001$

** Wald Chi-square test showed a significant difference at $\mathrm{p}<0.05$

Table 7 Effect of usage characteristics and demographics on Facebook advertising knowledge

* Wald Chi-square test showed a significant difference at $\mathrm{p}<0.001$

** Wald Chi-square test showed a significant difference at $\mathrm{p}<0.05$

\begin{tabular}{lccc}
\hline Independent variables & \multicolumn{3}{l}{ Type III } \\
\cline { 2 - 4 } & Wald Chi-Square & df & P \\
\hline Access & 10.062 & 2 & $.007^{* *}$ \\
Length of usage & 7.322 & 4 & .686 \\
Log on frequency & 2.321 & 4 & .693 \\
Log on duration & 16.877 & 4 & $.000^{*}$ \\
Profile update incidence & 21.792 & 4 & $.000^{*}$ \\
Gender & .240 & 1 & .662 \\
Age & 22.935 & 2 & .739 \\
Ethnic orientation & 26.220 & 3 & $.000^{*}$ \\
\hline
\end{tabular}

\begin{tabular}{lccl}
\hline Independent variables & \multicolumn{2}{l}{ Type III } \\
\cline { 2 - 4 } & Wald Chi-Square & df & P \\
\hline Access & 8.109 & 2 & $.017^{* *}$ \\
Length of usage & 3.861 & 4 & .425 \\
Log on frequency & 4.700 & 4 & .319 \\
Log on duration & 66.537 & 4 & $.000^{*}$ \\
Profile update incidence & 21.424 & 4 & $.000^{*}$ \\
Gender & .093 & 1 & .760 \\
Age & 2.038 & 2 & .361 \\
Ethnic orientation & 36.630 & 3 & $.000^{*}$ \\
\hline
\end{tabular}

display a general convergence of responses. A non-parametric one-sample bi-nominal standardized test was used to establish whether there was a significant difference. The test revealed that for all of the items of both scales, there was a significant difference at $\mathrm{p}<0.001$. Furthermore, Tables 4 and 5 show a predominantly positive medium ( $\mathrm{r}$ $>0.3)$ to strong $(r>0.5)$ correlation between Facebook advertising awareness and knowledge scale items.

The GLM ANOVA (as mentioned in prior text), using the Wald's Chi-square and the post ad hoc Bonferroni pairwise comparisons [26] were used to establish significant differences between respondents' cognitive attitudes (dependent variables) towards Facebook advertising and their usage characteristics (independent variables) and demographic factors (independent variables). The GLM ANOVA was utilized owing to the unbalanced data, since standard errors are larger where there was a smaller number of observations for certain predictive factors (for example, there were few respondents who logged on to Facebook once a month), which the GLM takes into consideration and "normalizes" the results [64]. Tables 6 and 7 show the effect in terms of the Wald Chi-Square tests, which is based on the Bonferroni correction pairwise post hoc test among the estimated marginal means.

The Wald Chi-Square test revealed that there was a significant difference at $\mathrm{p}<$ 0.001 for awareness $(\mathrm{M}=3.35, \mathrm{SD}=0.852)$ as a result of Facebook advertising. 
No significant differences were found for length of usage, log on frequency, gender and age, whereas Bonferroni correction pairwise comparisons of estimated marginal means showed significant differences between the following variables:

Access $(p<0.05)$ : Facebook accessed via both $\mathrm{PC}$ and mobile device $(\mathrm{M}=3.32$, $\mathrm{SE}=0.038)$ showed higher awareness levels than when accessed either by PC (M $=3.21, \mathrm{SE}=0.046)$ or mobile device $(\mathrm{M}=3.24, \mathrm{SE}=0.043) . \mathrm{vLog}$ on duration $(\mathrm{p}$ $<0.001)$ : Respondents who logged on for $\leq 1 \mathrm{~h}(\mathrm{M}=3.16, \mathrm{SE}=0.036)$ displayed lower awareness levels than those who remained logged on for $2 \mathrm{~h}(\mathrm{M}=3.32$, SE $=0.041)$ and $3 \mathrm{~h}(\mathrm{M}=3.33, \mathrm{SE}=0.05)$.

Profile update incidence $(\mathrm{p}<0.001)$ : Respondents who updated their Facebook status daily $(\mathrm{M}=3.30, \mathrm{SE}=0.044)$ exhibited greater awareness than those who updated it 2-4 times a month $(\mathrm{M}=3.12, \mathrm{SE}=0.053)$; those who updated their Facebook status $2-4$ times a week $(\mathrm{M}=3.36, \mathrm{SE}=0.045)$ resulted in increased awareness in comparison to those who updated it $2-4$ times a month $(\mathrm{M}=3.12$, $\mathrm{SE}=0.053)$ and once a month $(\mathrm{M}=3.12, \mathrm{SE}=0.045)$.

Ethnic orientation $(\mathrm{p}<0.001)$ : White respondents $(\mathrm{M}=3.11, \mathrm{SE}=0.047)$ presented lower awareness levels as a result of Facebook advertising compared to Black $(\mathrm{M}=3.34, \mathrm{SE}=0.034)$ and Colored $(\mathrm{M}=3.30, \mathrm{SE}=0.040)$ respondents.

The Wald Chi-Square test revealed that there was a significant difference at $\mathrm{p}<$ 0.001 for knowledge $(\mathrm{M}=3.29, \mathrm{SD}=0.815)$ owing to Facebook advertising. No significant differences were found for length of usage, log on frequency, age and gender; however, Bonferroni correction pairwise comparisons of estimated marginal means revealed significant differences among the subsequent variables:

Access $(\mathrm{p}<0.05)$ : Facebook accessed via both PC and mobile device $(\mathrm{M}=3.28$, $\mathrm{SE}=0.037)$ showed greater knowledge levels when accessed either by PC $(\mathrm{M}=$ $3.18, \mathrm{SE}=0.044)$ or mobile device $(\mathrm{M}=3.20, \mathrm{SE}=0.042)$.

Log on duration ( $\mathrm{p}<0.001)$ : Respondents who logged on for $1 \mathrm{~h}(\mathrm{M}=3.06, \mathrm{SE}$ $=0.035)$ resulted in lower knowledge levels than those who remained logged in for $2 \mathrm{~h}(\mathrm{M}=3.29, \mathrm{SE}=0.039), 3 \mathrm{~h}(\mathrm{M}=3.29, \mathrm{SE}=0.047), 4 \mathrm{~h}(\mathrm{M}=3.27, \mathrm{SE}=$ $0.061)$ and $5 \mathrm{~h}(\mathrm{M}=3.22, \mathrm{SE}=0.059)$.

Profile update incidence ( $\mathrm{p}<0.001$ ): Respondents who updated their Facebook status daily $(\mathrm{M}=3.28, \mathrm{SE}=0.042)$ and $2-4$ times a week $(\mathrm{M}=3.31, \mathrm{SE}=0.042)$ exhibited increased knowledge levels in comparison to those who updated it 2-4 times a month $(\mathrm{M}=3.09, \mathrm{SE}=0.051)$.

Ethnic orientation $(\mathrm{p}<0.001)$ : White respondents $(\mathrm{M}=3.11, \mathrm{SE}=0.045)$ showed lower knowledge levels owing to Facebook advertising compared to Black ( $\mathrm{M}=$ 3.34, $\mathrm{SE}=0.032)$ and Colored $(\mathrm{M}=3.30, \mathrm{SE}=0.038)$ respondents.

\section{Discussion and implications}

\subsection{Key findings}

In terms of the first research question, the findings of this study confirmed that Facebook advertising undoubtedly created awareness among the Generation Y cohort in 
SA. eMarketer [20] found that consumers who were exposed to both paid and earned social media could assist organizations with increased brand awareness. Nielsen and Vizu [42] reported that marketers planned to continue to increase (63\%) their online advertising expenditure in 2013 in order to create direct responses and to establish brand awareness. Conversely, Hadija et al. [30] concluded that social network users did notice the advertising, but focused on the content, such as the newsfeed and friends' profiles. Although several of the advertisements on the SNS did catch their attention owing to design, color, tagline and so forth, these were quickly overlooked in favor of more stimulating content; however, this was only a small qualitative study that included twenty respondents. Therefore, advertising on Facebook is a marketing communication tool that appeals to young adults in SA and should not be ignored by marketers that effectively facilitate the first stage of the hierarchy-of-effects model. The research also disclosed that advertising on Facebook also resulted in increased levels knowledge amid Generation Y. Taylor et al. [61] revealed that if the users perceived SNS advertising as being informative, it would favorably influence their attitudes towards advertising, which is displayed on these SNS, whereas Burst Media [9] indicated that Internet consumers' primary reason why they followed companies and brands on SNS was to keep up-to-date with the latest information. However, Powers et al. [47] reported that consumers sometimes felt overwhelmed by the vast amount of online information and it was difficult to navigate through all of it, but this does not appear to hold true for South African Generation Y's sentiments, as they view Facebook advertisements as a good source of information to increase their knowledge of the featured companies, products and brands.

Mobile devices (cell phones, feature phones, smartphones and tablets) have certainly become a catalyst in making SNS accessible 24/7, but have not been considered as a good online advertising mechanism owing to the small size of the screen [23]. Furthermore, Ball State University [2] also reported that attitudes towards mobile advertising was generally not positive, with almost $70 \%$ stating their annoyance at receiving such advertisements and, consequently, $44 \%$ were less inclined to purchase the brand or product. However, in respect of the second research question, an interesting result of this inquiry concluded that mobile devices that are used in conjunction with computers resulted in the most effective Facebook marketing communication mechanism to reach Generation Y in SA. Wronski and Goldstruck [68] revealed that $87 \%$ of Facebook users in SA access this SNS via their mobile phones. Facebook [24] revealed that $83 \%$ or 1.12 million Facebook users across the globe check Facebook via their mobile phones. Numerous marketers have commenced with mobile marketing since it matches Generation Y's busy lifestyle and concentrates on applications that add value to consumers' experiences [32]. Hence, there is major potential for marketers in SA to target Generation Y and to receive good value from SNS advertising via mobile phones.

The analysis showed that SNA was most effective when young adults spent two of more hours logged on to Facebook, which is logical, since they would have more time to notice the advertisements. However, Generation Y tend to multi-task and use their mobile devices while on the move to access the Internet, SNS and to communicate, so do not spend long periods on Facebook at one time [56]. This study ratified that just under half of young adults in SA spend an hour or less on Facebook at one time, which 
is problematic for marketers, since this reduces the effectiveness of their marketing communications efforts and should find how to lead Generation Y on Facebook for longer. Hence, South African marketers should consider making use of Facebook's wide range of apps (Facebook is integrated with over 9 million websites and apps) and social plugins to keep users busy on the SNS platform for longer, thereby increasing chances of interaction with advertising. Common apps include games, listening to music and watching movies, whereas popular social plugins such as the like button, subscribe button, comments and single sign on registration plugins [25], all of which are available to marketers in one or more forms of marketing communications.

The more frequently Generation Y cohort members updated their profile on Facebook, the more effective the advertising in terms of creating awareness and generating knowledge. This makes rational sense, since increased activity on the SNS would increase the probability of users who interact with other elements such as the advertising. Marketers in SA could use Facebook's comprehensive metrics system to target potential consumers that displayed frequent update activities on their profiles. Furthermore, Facebook is continually innovating by launching new apps and social plugins, developing new products and purchasing companies that fit in with the Facebook mix, which necessitates that users should engage and update their profiles on a more regular basis.

Young adults from the White population group displayed lower levels of awareness and knowledge owing to Facebook advertising in comparison to the Black and Colored population groups. Statistics SA [58] disclosed that the White population has greater access to the Internet $(70.3 \%)$ compared to the Black $(29.4 \%)$ and Colored $(35.7 \%)$ population groups. Furthermore, the White young adults had possibly been exposed to the Internet at a younger age and accumulated more experience in dealing with marketing communications on SNS. The Black middle class (termed as the "Black Diamonds" by UCT Unilever Institute of Strategic Marketing) in SA has increased twofold from 8 to $16 \%$ of the population since 2004, and spend in the region of R400 billion per annum [48]. Furthermore, over three quarters of Black middle class children go to former "model C" or private schools and the number of Black Diamonds who have degrees has more than doubled. Black diamonds are online and digitally connected; with many accessing the Internet via their mobile phones (95\% of the Black middle class own mobile phones) [53]. Consequently, the percentage of Black SNS users has increased significantly over the past decade, especially in terms of the Generation Y cohort, as has their exposure to advertising on platforms such as Facebook, which represents a lucrative opportunity for marketers in SA owing to their positive cognitive sentiments.

\subsection{Theoretical implications}

Facebook advertising was found to have a positive influence on the cognitive attitudes of Generation Y, which supports the hierarchy-of-effects and communications of effect pyramid models that were formulated through research on traditional advertising. These models theorize consumers' move from low level hierarchical objectives, namely awareness and knowledge, to higher level hierarchical objectives such 
as intention-to-purchase and purchase, which are more demanding to achieve $[1,63]$. Consequently, it can be concluded that Facebook advertising is congruent with traditional advertising regarding lower levels of the hierarchy-of-effects and communications of effect pyramid models. The findings also substantiate that Facebook advertising yields similar cognitive attitudes compared to Internet advertising in developed countries $[10,65,70]$. Additionally, it can be theorized that the results of this study were similar to the outcomes of other SNS investigations, which have been conducted in developed countries, thus confirming corresponding cognitive attitudes between emerging nations (such as SA) and first world nations [31,38,39,50,66]. Bolton et al. [8] hypothesized that globalization could result in a rise of homogeneousness owing to the Generation Y cohort's SNS usage, but the veracity of this postulation was in doubt because of the relatively poor information technology access, resources and infrastructure that is evident in emerging countries such as SA. Several of the aforementioned inquiries that were implemented in the US and Europe similarly examined Generation Y $[31,38,50]$, thereby demonstrating that South African Generation Y cohort members have similar cognitive attitudes to their international counterparts, which confirms Bolton et al.'s [8] supposition to be accurate. Thus, this study has made significant additions to advance cohort, attitudinal and SNA research in a developing country.

Particular usage characteristics such as how Facebook was accessed, log on duration and profile update incidence had an impact on Generation Y's awareness and knowledge pertaining to Facebook advertising. A number of inquiries considered an array of usage factors among South African users [14,16,32,52] and equivalent high usage tendencies were determined by this research, but prior research observed SNS collectively; none conducted cross analysis between the SNS and usage elements; or regarded the attitudinal effect on advertising. Hence, this study makes a valuable contribution to SNS research in South Africa, not only by confirming the high usage of South African Facebook users, but also by determining, which usage factors resulted in more favorable attitudes as a result of SNA. From a global perspective, few investigations have considered the impact of usage characteristics on attitudes towards SNA, therefore, a pioneering addition had also been made in terms of an international context.

Ethnic orientation had a favorable influence on the cognitive attitudes of Black Generation Y in SA. Several studies described certain ethnic orientation traits or outlined the proportions of different population groups of SNS users in SA: De Lanerolle [14] asserted that two out of three Internet users spoke an African language; Dlodlo and Dhurup [16] confirmed that there was a high number of Black Generation Y SNS users; and Bevan-Dye et al. [6] established materialism, status-consumption and ethnocentrism predispositions among Black Generation Y students. However, none considered the impact of ethnic orientation on attitudes towards SNA, and so another significant addition affirms the effect of SNA among Facebook users of various population groups in SA; thereby heeding Jordaan [32] call to investigate whether there was a difference between Generation Y ethnic groups in terms of their perceptions of different media. Few international inquiries have contemplated the effect of ethnic orientation attitudes towards SNA, hence another original contribution has been made in terms of an international context. 


\subsection{Implications for practice}

Facebook had a significant attitudinal impact on awareness and knowledge amongst Generation Y in SA. This result supports the decision by marketers in SA to spend a substantial amount of their promotional budgets on social media advertising. However, it should be taken into account that Generation Y has not yet formed permanent consumer behavior tendencies, and since a number of them are unemployed or students and have limited income, it may result in low levels of the higher hierarchy-of-effects stages, especially in terms of the ultimate purchase. Nevertheless, South African marketers should take the abovementioned results into cognizance in an endeavor to raise awareness and knowledge levels among Generation Y.

The researcher anticipated that Facebook advertising, which is accessed by mobile devices would result in more favorable cognitive attitudes than desktops, however, highest awareness and knowledge levels were found when Facebook was accessed by both PC and mobile device. Still, marketers should take mobile marketing communications into consideration owing to the incremental adoption rate of mobile devices in SA. This research established that advertising on Facebook had the highest impact on cognitive attitudes in relation to the longer the amount of time spent on the social medium by Generation Y. Though, this inquiry established that nearly half of Generation Y spent one hour or less on the SNS per log on period, which is disadvantageous to the advertising efforts. Hence, South African marketers should aim to include an assortment of Facebook's extensive collection of social plugins and apps in an effort to keep young adults entertained on Facebook for lengthier time periods, which should result in more favorable cognitive attitudes towards their organization and brands. This study also determined that Generation Y members who updated their Facebook profiles more frequently resulted in the most positive cognitive attitudes. Accordingly, organizations and marketers in SA could use Facebook metrics to target the most active Generation Y users, as well as Facebook's social plugins and apps as part of their promotion strategy which may have a favorable effect on their profile updating frequency [25].

Black and Colored ethnic groups showed higher awareness and knowledge levels than the White population group. Petzer and Meyer [45] revealed that a substantial Black middle class had grown with greater spending power than their White compatriots. However, almost one in four South Africans live below the poverty line, but also have future aspirations, which has stimulated a demand for products and services that are not customarily associated with bottom-end consumers. Consequently, young adults of color are a possible lucrative target market, which has in recent times received greater exposure to advertising on social media that could be taken advantage of by astute marketers.

There are huge opportunities for both international and local organizations to exploit the shift to digital media (SNS and mobile) marketing communications by developing their marketing communication strategies to actively engage and connect with consumers across multiple interactive conduits [28]. SNS media is growing incrementally as a promotional tool, but it is up to organizations and marketers to recognize that the needs, wants and expectations of young consumers are constantly changing and, therefore, this should be considered when advertising on SNS such as Facebook [40]. 
Additionally, the advertisements should be stimulating, entertaining and interactive to appeal to Generation Y who are particularly unpredictable and sometimes challenging to reach. Marketers in SA must endeavor to comprehend what prospective consumers are doing on social mediums such as Facebook, and should be willing to adjust social media marketing communication strategies, as a result of consumer feedback, changes that occur in the environment and academic research in order to improve their effectiveness. This research adds greater insight into the efficient use of the marketers' arsenal of social media marketing communication tools. It provides South African marketers with an understanding of the cognitive attitudes, usage behavior and demographic variables that may allow them to ultimately influence purchase decisions, via Facebook advertising, among the ambivalent Generation Y cohort.

\section{Limitations and future research}

This study is not without limitations and some will provide an avenue for further research. No distinction was made between the between different types of Facebook advertising and the effect thereof was examined collectively. Future inquiries could examine the influence that the different types of Facebook advertising have on attitudes. The research focused on a single cohort, but a comparative study of the other cohorts would provide a more comprehensive framework of the attitudinal influence of Facebook advertising. This study represents a 'snap shot' of attitudes toward SNA, whereas further research could consider the progression of attitudes towards Facebook advertising over an extended period of time, in other words, a longitudinal research design. Qualitative research would also provide greater depth of understanding of young adults' attitudes, and other attitude components such as cognitive and conative attitudes, which should also be investigated. Furthermore, additional research on other popular SNS such as Twitter, YouTube, LinkedIn and Google+ could be affected, as could comparative studies with other developing and first world nations.

Open Access This article is distributed under the terms of the Creative Commons Attribution License which permits any use, distribution, and reproduction in any medium, provided the original author(s) and the source are credited.

\section{References}

1. Aaker, D. A., \& Carman, J. M. (1982). Are you over advertising? Journal of Advertising Research, 22(4), 57-70.

2. Ball State University. (2012). College students challenge marketers on mobile. http://www.emarketer. com/Article/College-Students-Adopt-Mobile-Across-Board/1009301. Accessed 5 July, 2013

3. Bannister, A., Kiefer, J., \& Nellums, J. (2013). College students' perceptions of and behaviors regarding Facebook advertising: An exploratory study. The Catalyst, 3(1), 1-20.

4. Barreto, A. M. (2013). Do users look at banner ads on Facebook. Journal of Research in Interactive Marketing, 7(2), 119-139.

5. Belch, G. E., \& Belch, M. A. (2012). Advertising and promotion: An integrated marketing communication perspective (9th ed.). New York: McGraw-Hill. 
6. Bevan-Dye, A. L., Garnett, A., \& de Klerk, N. (2012). Materialism, status consumption and consumer ethnocentrism amongst black Generation Y students in South Africa. African Journal of Business Management, 6(16), 5578-5586. 11.

7. Bischoff, W. (2012). Mobile advertising now on Facebook in South Africa. http://www.bizcommunity. com/Article/196/12/78197.html. Accessed 4 July, 2013

8. Bolton, R. N., Parasuraman, A., Hoefnagels, A., Migchels, N., Kabadayi, S., Gruber, T., et al. (2013). Understanding Generation Y and their use of social media: A review and research agenda. Journal of Service Management, 24(3), 245-267.

9. Burst Media. (2013). Google+ trumps Twitter, earning second place for total US social networkers. http://www.emarketer.com/Article/Google-Trumps-Twitter-Earning-Second-Place-TotalUS-Social-Networkers/1009937. Accessed 11 July, 2013

10. Chatterjee, P. (2008). Are unclicked ads wasted? Enduring effects of banner and pop-up ad exposures on brand memory and attitudes. Journal of Electronic Commerce Research, 9(1), 51-61.

11. Chikandiwa, S. T., Contogiannis, E., \& Jembere, E. (2013). The adoption of social media marketing in South African banks. European Business Review, 25(4), 365-381.

12. Churchill, G. A. (1994). Marketing research: Methodological foundations. Ohio: Thomson Learning.

13. Curran, K., Graham, S., \& Temple, C. (2011). Advertising on Facebook. International Journal of E-Business Development, 1(1), 26-33.

14. De Lanerolle, I. (2012). The New Wave: Who connects to the Internet, how they connect and what they do when they connect. Johannesburg: South African Network Society Project \& University of Witwatersrand.

15. Digital Fire. (2012). Understanding the Black Diamond market. http://www.digitalfire.co.za/blog/ understanding-the-black-diamond-market/. Accessed 20 November, 2013

16. Dlodlo, N., \& Dhurup, N. (2013). Examining social media dimensions among a cohort of Generation Y consumers in South Africa. Mediterranean Journal of Social Sciences, 4(14), 329-338.

17. Ducoffe, R. H. (1996). Advertising value and advertising on the web. Journal of Advertising Research, 36(5), 21-35.

18. Duncan, C. P., \& Nelson, J. E. (1985). Effects of humor in a radio advertising experiment. Journal of Advertising, 14(2), 33-64.

19. Econsultancy \& Adobe. (2012). Marketers still can't tie social to bottom line. http://www.emarketer. com/Article.aspx?R=1009340. Accessed 7 July, 2013

20. eMarketer. (2012). Social media key influencer in multi-exposure purchase path. http://www.emarketer. com/Article.aspx?R=1008845\&ecid=a6506033675d47f881651943c21c5ed4. Accessed $10 \mathrm{July,} 2013$

21. eMarketer. (2013a). Google takes home half of worldwide mobile internet ad revenues. http://www. emarketer.com/Article/Google-Takes-Home-Half-of-Worldwide-Mobile-Internet-Ad-Revenues/100 9966. Accessed 7 July, 2013

22. eMarketer. (2013b). Social networking reaches nearly one in four around the world. http://www.emarke ter.com/Article/Social-Networking-Reaches-Nearly-One-Four-Around-World/1009976. Accessed 4 July, 2013

23. EyeTrackShop. (2012). Will mobile advertisements make a mark for Facebook? http://www.emarketer. com/Article.aspx?R=1009239. Accessed 4 July, 2013

24. Facebook. (2014a). Company info. https://newsroom.fb.com/company-info/. Accessed 28 November, 2014

25. Facebook. (2014b). Platform. https://newsroom.fb.com/Platform. Accessed 22 November, 2013

26. Field, A. (2009). Discovering statistics using SPSS (3rd ed.). London: Sage.

27. Geissler, G. L., Zinkhan, G. M., \& Watson, R. T. (2006). The Influence of home page complexity on consumer attention, attitudes, and purchase intent. Journal of Advertising, 35(2), 69-80.

28. Ginsberg, J. (2012). Renewed mobile Facebook focus, iPhone 5 launch: Ignore mobile at your peril. http://www.bizcommunity.com/Article/196/78/81954.html. Accessed 1 July, 2013

29. Grinnell, R. M., \& Unrau, Y. A. (2008). Social work research and evaluation: quantitative and qualitative approaches. New York: Oxford University Press.

30. Hadija, Z., Barnes, S. B., \& Hair, N. (2012). Why we ignore social networking advertising. Qualitative Market Research: An International Journal, 15(1), 19-32.

31. Hansson, L., Wrangmo, A., \& Søilen, K. S. (2013). Optimal ways for companies to use Facebook as a marketing channel. Journal of Information, Communication and Ethics in Society, 11(2), 112-126.

32. Jordaan, Y., Ehlers, L., \& Grove, J. M. (2011). Advertising credibility across media channels: perceptions of Generation Y consumers. Communicare, 30(1), 1-20. 
33. Justplay. (2012). South Africans want free stuff on Facebook. http://www.bizcommunity.com/Article/ 196/19/76695.html. Accessed 2 July, 2013

34. Kelly, L., Kerr, G., \& Drennan, J. (2010). Avoidance of advertising in social networking sites: The teenage perspective. Journal of Interactive Advertising, 10(2), 16-27.

35. Kent, A. (2009). Ready to spread your social media marketing wings with nifty applications? http:// www.marketingmix.co.za/pebble.asp?relid=4463. Accessed 13 June, 2012

36. Lesame, N. (2013). Vision and practice: The South African information society experience. Journal of Multidisciplinary Research, 5(1), 73-90.

37. Levin, J. (2013). Generation Next 2013 youth brand survey: Word from the field. Sunday Times, 2, June 2.

38. Logan, K., Bright, L. F., \& Gangadharbatla, H. (2013). Facebook versus television: Advertising value perceptions among females. Journal of Research in Interactive Marketing, 6(3), 164-179.

39. McCarthy, J., Rowley, J., Ashworth, C. J., \& Pioch, E. (2014). Managing brand presence through social media: The case of UK football clubs. Internet Research, 24(2), 43-75.

40. Middleton, J. (2009). Business benefits of Facebook. www.themarketingsite.com/live/content.php? Item_ID=9641. Accessed 13 June, 2013.

41. Moore, M. (2012). Interactive media usage among millennial consumers. Journal of Consumer Marketing, 29(6), 436-444.

42. Nielsen \& Vizu. (2013). Brand marketers put more emphasis on social, mobile, video. http://www. emarketer.com/Article/Brand-Marketers-Put-More-Emphasis-on-Social-Mobile-Video/1010144. Accessed 2 September, 2013

43. Okazaki, S., \& Taylor, R. T. (2013). Social media and international advertising: Theoretical challenges and future directions. International Marketing Review, 30(1), 56-71.

44. Pallant, J. (2010). SPSS survival manual (4th ed.). New York: McGraw-Hill.

45. Petzer, D. J., \& De Meyer, C. F. (2013). Trials and tribulations: Marketing in modern South Africa. European Business Review, 25(4), 382-390.

46. Pike, W. (2009). Tweeting yourself into an empty nest. http://www.marketingmix.co.za/pebble.asp? relid=9149. Accessed 13 June, 2012

47. Powers, T., Advincula, D., Austin, M. S., Graiko, S., \& Snyder, J. (2012). Digital and social media in the purchase decision process. Journal of Advertising Research, 52, 479-489.

48. Radebe, K. (2013). Young, middle class and black. http://www.moneyweb.co.za/moneywebeconomic-trends/young-middle-class-and-black. Accessed 20 November, 2013

49. Ramnarain, Y., \& Govender, K. K. (2013). Social media browsing and consumer behaviour: Exploring the youth market. African Journal of Business Management, 7(18), 1885-1893.

50. Ruane, L., \& Wallace, E. (2013). Generation Y females online: Insights from brand narratives. Qualitative Market Research: An International Journal, 16(3), 315-335.

51. Saxena, A., \& Khanna, U. (2013). Advertising on social network sites: A structural equation modeling approach. Vision, 17(1), 17-25.

52. Shambare, R., Rugimbana, R., \& Sithole, N. (2012). Social networking habits among students. African Journal of Business Management, 6(2), 578-586.

53. Shevel, A. (2013). Black Diamonds outshine whites. http://www.bdlive.co.za/national/2013/04/28/ black-diamonds-outshine-whites. Accessed 20 November, 2013

54. Shipman, S. (2010). Study reveals what attracts Generation Y go-getters. Management Today, 28(6), 48.

55. Siemens Enterprise Communications \& Yankee Group. (2010). Businesses are missing out on social media opportunities. http://www.marketingmix.co.za/pebble.asp?relid=11415. Accessed 13 June, 2013

56. Smith, K. T. (2012). Longitudinal study of digital marketing strategies targeting Millennials. Journal of Consumer Marketing, 29(2), 86-92.

57. Smith, S. D., Caruso, J. B., \& Kim, J. (2010). The ECAR study of undergraduate students and information technology. Colorado: Educause.

58. Statistics, S. A. (2012). Census 2011: In brief. Pretoria: Statistics South Africa.

59. Tavakol, M., \& Dennick, R. (2011). Making sense of Cronbach's alpha. International Journal of Medical Education, 2, 53-55.

60. Taylor Nelson Sofres \& MWEB. (2009). Friendship 2.0. http://www.mweb.co.za/services/friendship/ downloads/Friendship\%202.0\%20presentation\%20for\%20Microsite.pdf. Accessed 13 June, 2013 
61. Taylor, D. G., Lewin, J. E., \& Strutton, D. (2011). Friends, fans and followers: Do ads work on social networks? Journal of Advertising Research, 51, 258-275.

62. TBG Digital. (2012). Getting the most out of Facebook advertisements. http://www.emarketer.com/ Article.aspx?R=1009144. Accessed 2 July, 2013

63. Tellis, G. J. (1988). Advertising exposure, loyalty, and brand purchase: A two-stage model of choice. Journal of Marketing Research, 25(2), 134-144.

64. Van Schalkwyk, D. (2012). Quantitative statistics. Cape Town: CPUT.

65. Wang, Y., \& Sun, S. (2010). Assessing beliefs, attitudes, and behavioral responses toward online advertising in three countries. International Business Review, 19, 333-344.

66. Whiting, A., \& Williams, D. (2013). Why people use social media: A uses and gratifications approach. Qualitative Market Research: An International Journal, 16(4), 362-369.

67. Wilson, C. (2013). Online advertising to boom in SA: PWC. http://www.techcentral.co.za/onlineadvertising-to-boom-in-sa-pwc/43930. Accessed 27 November, 2014

68. Wronski, M., \& Goldstruck, A. (2013). SA social media landscape 2014. Johannesburg: World Wide Worx \& Fuseware.

69. Wronski, M. \& Goldstruck, A. (2014). Facebook gets equal take-up by males and females. http://www. bizcommunity.com/Article/196/19/120926.html. Accessed 27 November, 2014

70. Yoo, C. Y., Kim, K., \& Stout, P. A. (2010). Assessing the effects of animation in online banner advertising: Hierarchy effects model. Journal of Interactive Advertising, 4(2), 49-60. 